\title{
A NOVA EXEGESE DOS CONTRATOS DE ADESÃO APÓS O ADVENTO DO CÓDIGO DE DEFESA DO CONSUMIDOR.
}

\author{
Luiz Miguel Schneider*
}

\section{RESUMO:}

O presente artigo denota, primeiramente, a origem e a evolução das relações contratuais numa sociedade de consumo. Após, elenca as principais características dos contratos de adesão e a nova hermenêutica dada a esses, em consonância ao princípio da boa - fé objetiva e o Código de Defesa do Consumidor.

PALAVRAS-CHAVE: Contratos de adesão. Código de Defesa do Consumidor. Boa-fé objetiva.

\section{ABSTRACT:}

The present article indicates first the origin and evolution of contractual relations in a society of consumerism. After, it gives the main characteristics of adhesion contracts and the new hermeneutics given to these, according to the principles of objective good-faith and the Consumer's Defense Code.

KEY-WORDS: Adhesion contracts. Consumer's Defense Code. Objective good-faith.

*Acadêmico do $6^{\circ}$ semestre do Curso de Direito da UFSM.

\section{INTRODUÇÃ̃O}

Os contratos são reais frutos da situação econômica que domina na época de seu surgimento, sendo assim, em uma sociedade não industrializada onde são perfeitamente identificados os sujeitos da relação negocial, prepondera a autonomia de vontade, o embate de idéias para a formulação do contrato.

Já numa sociedade industrializada, como a hodierna, que preza pela dinâmica negocial a vontade de um dos contratantes irá predominar em detrimento da do outro. Visto que, não há como as partes estipularem uma a uma as cláusulas que irão pautar essa relação, surgindo, dessa feita, os contratos em massa, como os contratos de adesão.

Nesse tipo contratual como domina a vontade de um dos contratantes, esse usa dessa prerrogativa, em inúmeras vezes, para atender seus preceitos. Estipulando no contrato cláusulas abusivas, desproporcionais que oneram demasiadamente a parte vulneráve $^{1}$ da relação. Tentando dirimir esses efeitos o legislador pátrio institui a lei 8078/90, o Código de Defesa do Consumidor.

Tentando demonstrar a nova interpretação dada aos contratos de adesão após o advento dessa lei, será feita uma análise evolutiva do mesmo, assim como, uma breve explanação de suas características basilares. A seguir será dada ênfase ao advento do Código de Defesa do Consumidor, e toda questão principiológica que o circunda. 


\section{CONTRATOS DE ADESÃO}

\subsection{Origens dos contratos de adesão}

Aprioristicamente, a concepção contratual era estabelecida pela convergência de vontades entre duas ou mais partes. Essas que, em uma suposta igualdade social e econômica formulavam as cláusulas que iriam pautar a relação contratual. Então, o contrato surgia desse mútuo embate de idéias e propostas, cujo resultado seria colocado no respectivo instrumento contratual.

A partir do séc.XIX, em virtude da massificação das relações de consumo e da produção em alta escala, esse tipo contratual acabou se mostrando inoperante, anacrônico para atender as atuais demandas do mercado, caindo, assim, em desuso.

E é nesse contexto que surge o contrato de adesão visando dinamizar as relações contratuais dotando-as de efetividade e as adequando a realidade vigente.

Então o surgimento desse tipo contratual é um sinal dos tempos ${ }^{2}$ modernos onde as cláusulas da relação contratual são impressas antecipadamente, bastando a adesão do contratante. Frisa-se, que com o advento do contrato de adesão macula-se um dos princípios norteadores das relações contratuais o da autonomia da vontade.

\subsection{Características dos contratos de adesão}

Os contratos de adesão, em termos específicos, se denotam pela oposição a idéia de paridade, pois não há possibilidade de qualquer embate entre as partes para formulação das cláusulas, sendo que um dos contratantes se limita a aceitar o que já foi predeterminado, é um contrato característico de uma sociedade de consumo, se destinando a um número indeterminado de pessoas.

$\mathrm{Da}$ caracterização esposada se retiram fundamentos basilares desse tipo contratual, que são a predeterminação, ou seja, as cláusulas nele estipuladas são formuladas pelo livre alvitre de uma das partes da relação contratual. A generalidade, pois sendo um contrato em massa é destinado a um número indeterminado de pessoas e pela uniformidade das cláusulas nele estipuladas, sendo que as mesmas são formuladas, independentemente da pessoa com quem se está a negociar. Além, logicamente, da imutabilidade de suas disposições cabendo ao oblato aceitar ou não o que vem predisposto.

${ }^{2}$ Qualifica - se como um sinal dos tempos atuais, em que as relações entre a massa popular e os centros comerciais se travam através de condições impressas antecipadamente, sujeitando- se os compradores interessados a simplesmente aceitar as exigências, fora de qualquer discussão(LOPES apud RIZZARDO, 2006,p.99) 
Há alguns autores que ainda denotam o monopólio de uma determinada atividade, como um elemento definidor dos contratos de adesão, entre esses vincula-se, Orlando Gomes(1997, p.119), que, assim preceitua "O que caracteriza o contrato de adesão propriamente dito é a circunstância de que aquele a quem é proposto não pode deixar de contratar, porque tem necessidade de satisfazer a um interesse que, por outro modo, não pode ser atendido."

Ademais, muitos dos serviços prestados à sociedade, hodiernamente, em virtude da massificação das relações de consumo e o dinamismo das relações contratuais se da através desse tipo contratual. Não obstante, há empresas que monopolizam determinada atividade comercial, como serviços de água e de luz, cerceando ainda mais a liberdade de contratação do consumidor, que se vê literalmente compelido a pactuar com o que está estipulado no contrato. Visto que, não lhe resta outro meio de buscar o produto no mercado ${ }^{3}$.

Então, através de uma simples análise dos contratos de adesão, constata-se que o predisponente possui uma enorme superioridade negocial em relação ao aderente.

Como, já frisado, é uma característica desse instituto a formulação antecipada das cláusulas contratuais. Então, em inúmeras vezes, usando dessa prerrogativa e assessorado por uma equipe técnica, o predisponente formula cláusulas com uma linguagem extremamente técnica e rebuscada dificultando, assim, o entendimento do aderente, além de estabelecer disposições desproporcionais que não se coadunam com o nosso ordenamento jurídico, que são as denominadas cláusulas abusivas. Essas cláusulas caracterizam-se, de modo geral, pela desproporção entre a prestação e contraprestação gerando, assim, uma onerosidade excessiva para o contratante que, muitas vezes, contrata seja por ingenuidade ou compelido por uma necessidade, pois inúmeros serviços são monopolizados no mercado consumidor.

Provocando, dessa feita, uma visível disparidade entre direitos e obrigações dos contratantes, onde o aderente se vê compelido a pagar uma prestação desproporcional e extremamente abusiva. E essa excessiva e abrupta desvantagem, que é quase uma característica intrínseca dos contratos em massa.

É imperioso salientar, que em virtude do dinamismo das relações contratuais, e a massificação das relações de consumo, o contrato de adesão se tornou um meio imprescindível para tornar mais célere e efetiva a atividade negocial. Já que,

${ }^{3} \mathrm{O}$ contrato de adesão é um contrato estereotipado, estandardizado, lógico alheio a qualquer restrição mental da parte aderente, por vezes com inteira ausência de determinação, porque via de regra, a coletividade a que é oferecido não tem mesmo opção de recusa útil em aderir, por se achar diante de uma atividade mercantil sob monopólio ou oligopólio.( SIDOU apud RIZZARDO,2006,p.99) 
atualmente, é impossível imaginar uma grande empresa, como uma empresa no ramo de eletrodomésticos pautando com o contratante, todas as disposições que iram regular a relação contratual.

Mas, em virtude das abusividade contidas nesse tipo contratual onde a parte vulnerável sempre é a mais prejudicada e atendendo ao reclames de vários segmentos da sociedade, foi institucionalizado o Código de Defesa do Consumidor. Uma norma que surgiu com o intuito de estabelecer a igualdade material e a equidade contratual.

\section{CÓdIGO DE DEFESA DO CONSUMIDOR E A NOVA CONCEPÇÃO PRINCIPIOLÓGICA}

Visando coibir os excessos ocasionados pelas relações contratuais em massa, principalmente as oriundas dos contratos de adesão, esses que em virtude de suas características causam uma real desproporção entre fornecedor e consumidor. $\mathrm{O}$ legislador institui uma norma de cunho social, onde o Estado passa a ter maior gerência nas relações contratuais intervindo , assim, de um modo mais contundente, efetivo com o escopo de dirimir as abrutais desigualdades existentes entre os contratantes.

Então, pode -se aduzir que o advento da lei 8078/90 que institui o Código de Defesa do Consumidor (CDC) estabelece a igualdade material entre os contratantes, valendo- se de um conceito histórico de justiça "Tratar os desiguais de uma forma desigual, até onde os mesmos desigualam, buscando, dessa forma, adequar-se as mais modernas concepções principiológicas, como o princípio da boa-fé objetiva,da relativização da força dos contratos e o da vulnerabilidade.

Um dos princípios norteadores do CDC, como já salientado, é o da boa-fé objetiva, que aduz o comportamento que deverá ser pautado em uma dada relação negocial,limitando,assim, a autonomia de vontades das partes contratantes.

\subsection{O princípio da Boa-Fé objetiva}

O CDC é uma norma inovadora no ordenamento jurídico pátrio, pois está pautado nas novas concepções principiológicas das relações contratuais como a boa-fé objetiva e seus deveres anexos, a relativização da força obrigatória dos contratos e o princípio da vulnerabilidade do consumidor .

Essas novas concepções vão dar uma nova exegese para as relações contratuais de consumo, como a delimitação da autonomia da vontade das partes nos contratos e amplitude dos efeitos de uma relação contratual. 
A delimitação das vontades partes na relação negocial é o principal escopo do princípio da boa-fé- objetiva. No caso dos contratos de adesão, o legislador restringiu a autonomia de vontade da parte economicamente mais forte da relação contratual, pois como já frisado esse que estipula todas cláusulas que irão pautar dado negócio jurídico, estabelecendo, assim, a igualdade material entre os contratantes.

Então, a boa-fé objetiva elenca novos deveres e novos limites aos que ocupam as posições contratuais, indica o comportamento que o homem médio, probo deve pautar nas relações contratuais. Conforme aduz Marques(2005, p.216): "Boa-fé objetiva significa,uma atuação refletindo, pensando no outro, no parceiro contratual, respeitando-o, respeitando seus interesses legítimos, suas expectativas razoáveis, seus direitos, agindo com lealdade, sem abuso, sem obstrução, sem causar lesão ou desvantagem excessiva."

Além de possuir essa função principal de delimitar, dar contornos precisos a autonomia de vontade das partes na relação contratual, a boa-fé objetiva traz concomitantemente uma série de deveres anexos ${ }^{4}$, que são aqueles intrínsecos a uma dada relação contratual.

Como o dever de informação, sendo esse de suma importância nas relações de consumo, caracterizando-se como o dever que possui o fornecedor de prestar informações fidedignas a respeito do produto. Um exemplo típico é do plano de saúde, pois o fornecedor do serviço deve avisar o consumidor das eventuais carências do plano, assim como, sua área de abrangência.

Esse dever de informação inclui o dever de uma redação clara das cláusulas contratuais, considerando a condição leiga da parte contratante. Esse também tem sido o entendimento do $\mathrm{STJ}^{6}$ alegando que nos contratos de adesão as cláusulas deverão ser redigidas com clareza e destaque para que não fuja da percepção leiga.

Por fim, da argumentação esposada e em consonância ao que apregoa a melhor doutrina, como Cláudia Lima Marques e Ruy Rosado Aguiar, são três as principais funções do princípio da boa-fé objetiva, quais sejam, a teleológica apresentando critérios para uma melhor interpretação dos contratos, sempre visando estabelecer a

\footnotetext{
4 Marques(2005,p.220), assim aduz acerca dos deveres anexos"Apesar de no Brasil consagrarmos a expressão alemã de deveres anexos ou secundários, enquanto contratuais, trata - se de verdadeiras obrigações (obrigações acessórias como denominam os franceses)ao indicar que a relação contratual obriga não somente ao cumprimento da obrigação principal mas também ao cumprimento de várias obrigações acessórias.

${ }^{6}$ “Seguro-saúde -Limite temoporal de internação - Cláusula limitativa - Redação com detaque - A Segunda Seção decidiu ser nula a cláusula limitativa do período de internação hospitalar do segurado(art.51 do CDC) - Vulnera a lei a decisão que considera válida cláusula limitativa de obrigação da estipulante, inserida no contrato sem destaque."(art.54,§ $4^{\circ}$, do CDC)-Recurso conhecido e provido"(Resp.214237/RJ,Min.Ruy de Rosado de Aguiar).
} 
igualdade no plano material, visando sempre atender o caráter social e protecionista da norma, a criação de deveres anexos como o já frisado, dever de informar.

E ainda a função limitativa, evitando a feitura de cláusulas desproporcionais, que possam levar a situações de desequilibro, onerando a parte mais vulnerável da relação.

Outra inovação trazida à tona com o CDC, foi a relativização da força obrigatória dos contratos, vencendo, dessa feita, o velho princípio da Pacta Sunt Servanda.

\subsection{Relativização da força obrigatória dos contratos}

Esse postulado denota que reconhecida uma cláusula contratual, que gere um ônus excessivo para uma das partes contratantes ou que afronte a ordem jurídica vigente, como a prevista nos inciso IV, do art.51 do Código de Defesa do Consumidor, terá seus efeitos relativizados a fim de preservar a equidade contratual.

Esse princípio é um real paradoxo ao da pacta sunt servanda, o qual apregoa que uma vez manifestada a vontade das partes numa relação contratual, estas ficariam ligadas por um vínculo. De onde surgiria direitos e obrigações para ambas as partes, com força obrigatória, que deveriam necessariamente ser cumpridos.

O papel gerenciador do Estado Social, no trato das relações contratuais fica ainda mais evidente através desse princípio, pois o Estado delimita o campo de atuação dos particulares ao formularem as cláusulas. E aquelas formuladas que ultrapassem esses limites serão nulas e terão seus efeitos exauridos.

Então, esse princípio impede que a parte vulnerável da relação, que na maioria das vezes, aderiu ao contrato sem ter pleno conhecimento de seu conteúdo ou compelido por uma necessidade, venha a sofrer os efeitos de cláusulas desproporcionais, abusivas, assim denominadas pelo CDC.

Outra inovação preconizada pelo CDC e que tem o real escopo de estabelecer uma igualdade material entre os negociantes, principalmente nos contratos de adesão, é o princípio da vulnerabilidade.

\subsection{PRINCÍPIO DA VULNERABILIDADE}

Como já salientado, um dos principais problemas que circundam as relações contratuais é o desequilíbrio existentes entre os contratantes, visto que o pólo mais fraco da relação jurídica, não pode discutir o que vem preestabelecido no contrato, mesmo sabendo que essa condição é abusiva. 
Visando estabelecer uma paridade de forças entre os contratantes é perfeitamente justificável um tratamento desigual ${ }^{7}$, protegendo o vulnerável, tanto no plano fáctico, como no econômico. E não foi outra a atitude tomada por nosso legislador pátrio ao preconizar no art.4,I, do CDC, que o consumidor é parte vulnerável nas relações contratuais.

Preceituando acerca do conceito de vulnerabilidade, assim, aduz Marques(2005,p.320): “A vulnerabilidade não é pois, o fundamento das regras de proteção do sujeito mais fraco, é apenas a explicação destas regras ou da atuação do legislador, é a regra para sua boa aplicação, é a noção instrumental que guia e ilumina a aplicação dessas normas protetivas e reequilibradoras, à procura do fundamento da igualdade e da justiça eqüitativa".

Calha salientar, em linhas gerais, que o conceito de vulnerabilidade ${ }^{8}$ não se confunde com o de hipossuficiência, sendo este de natureza processual e aquele de natureza material, ou seja, todos consumidores são presumivelmente considerados vulneráveis, mas a hipossuficiência depende de uma análise concisa no plano, concreto tendo em vista o art. $6^{\circ}$, inciso VIII do CDC.

A doutrina de modo geral apregoa existirem quatro tipos de vulnerabilidade, a técnica, a científica, a econômica e a informacional. Em temos gerais a vulnerabilidade técnica é aquela em que o consumidor não possui, ou possui pouco conhecimento acerca do produto e serviços que está adquirindo, ficando a mercê da pessoa com quem está a contratar.

Já a vulnerabilidade científica é a falta de conhecimentos específicos, tanto na seara jurídica como na econômica, um exemplo clássico, é a vulnerabilidade do consumidor firmando contrato de empréstimo frente uma instituição financeira. A vulnerabilidade econômica é resultado da disparidade de forças entre fornecedores e consumidores, sendo que aqueles possuem plenas condições de estabelecer apenas seus preceitos em uma relação, os contratos de adesão refletem bem isso.

E por fim há a vulnerabilidade informacional, considerada como "hipervulnerabilidade", por ser o fornecedor, em inúmeras vezes, o único detentor de informações acerca de um dado produto. Assim aduz Marques(2005,p.330):”Esta

\footnotetext{
${ }^{7}$ Dessa forma Marques(2005, p.53)O CDC brasileiro concentra-se justamente no sujeito de direitos, visa proteger este sujeito, sistematiza suas normas a partir desta idéia básica de proteção de apenas um sujeito "diferente" da sociedade de consumo: o consumidor. É um Código especial para "desiguais", para "diferentes" em relações mistas entre um consumidor e um fornecedor."

${ }^{8}$ A vulnerabilidade do consumidor é incindível do contexto das relações de consumo e independe de seu grau cultural ou e conômico, não admitindo prova em contrário, por não se tratar de mera presunção legal. É a vulnerabilidade, a qualidade intrínseca,ingênita,imanente e indissociável de todos que se colocam na posição de consumidor,pouco importando sua condição social ou econômica.(BONATTO apud BENJAMIN, 2001,P.46/47)
} 
vulnerabilidade informativa não deixa, porém, de representar hoje o maior fator de desequilíbrio da relação vis-à-vis dos fornecedores, os quais são os experts.."

\section{CONSIDERAÇÕES FINAIS}

É inconteste que os contratos de adesão são necessários para o pleno funcionamento da sociedade contemporânea, pois sem os mesmo não haveria com ter uma eficaz circulação de bens e serviços, pois hodiernamente, seria inimaginável a discussão de cláusula por cláusula para a feitura de um negócio jurídico.

Mas numa sociedade já marcada pala abrupta desigualdade, delegar plena autonomia ao predisponente para formular as cláusulas contratuais, é deixar ainda mais a mercê a parte hipossuficiente, que inúmeras vezes suporta encargos altíssimos, privações de direitos por estar compelido a contratar, por não haver outra empresa no mercado, ou mesmo por inexperiência.

Após o surgimento do Código de Defesa do Consumidor, essa realidade vem aos poucos sendo dirimida, pois o Estado através dessa norma de cunho social procura ter uma participação mais ativa na sociedade, como limitar a autonomia de vontade dos contratantes numa relação negocial.

Tratando-se, dos contratos de adesão o legislador limitou a autonomia do predisponente, que após o CDC não pode mais formular cláusulas a seu bel prazer, pois as cláusulas abusivas, são nulas de pleno direito, devendo as mesmas serem suscitadas até de ofício pelo Magistrado.

Visa, dessa forma, estabelecer a igualdade no caso concreto, que o consumidor ao aderir a um contrato tenha seus direitos resguardados e não fique mais a mercê do fornecedor, que na maioria das vezes busca atender seus preceitos.

\section{REFERÊNCIAS BIBLIOGRÁFICAS}

BRASIL. Constituição federal, código civil, código de processo civil / organizador Yussef Said Cahali. 5. ed., atual. e ampl. São Paulo: Editora Revista dos Tribunais, 2003

BELMONTE,Cláudio.Proteção Contratual do Consumidor:Conservação e redução do negócio jurídico no Brasil e em Portugal.Editora Revista dos Tribunais, 2002. GOMES,Orlando.Contratos, Rio de Janeiro. Editora Forense,1999. 
MARQUES,Claúdia Lima.Contratos no Código de Defesa do Consumidor:o novo regime das relações contratuais. $5^{\circ} \mathrm{ed}$. São Paulo: Editora Revista dos Tribunais, 2005.

RIZZARDO,Arnaldo.Contratos. $6^{\circ}$ ed.Rio de Janeiro:Editora Forense, 2005.

TARTUCE,Flávio. A função social dos contratos do Código de Defesa do Consumidor ao novo Código Civil.São Paulo:Editora Método,2005.

LÔBO, Paulo Luiz Netto. Princípios sociais dos contratos no CDC e no novo Código Civil. In: Jus Navigandi: http://www1.jus.com.br/doutrina/texto. Acesso em: 23 ago. 2007.

NUNES, Luiz Antonio Rizzatto. Comentários ao Código de Defesa do Consumidor: direito material (arts. $1^{\circ}$ a 54). São Paulo: Saraiva, 2000.

BONATTO, CLÁUDIO.Questões Controvertidas no Código de Defesa do Consumidor.Porto Alegre: Livraria do Advogado,2001 
